\title{
Um mundo sem devastação é possível: repensar a floresta como conceito, metáfora e espaço compartilhado
}

\author{
A world without devastation is possible: to rethink \\ the forest as a concept, metaphor and shared space
}

\author{
Luca Provenzano \\ Doutorando em Filosofia \\ Universidade Federal do \\ Rio de Janeiro \\ lucapro3@gmail.com \\ http://orcid.org/0000-0003- \\ 0829-4050

\section{Professor Associado \\ Universidade Federal \\ do Rio de Janeiro \\ ferfra3@gmail.com \\ http://orcid.org/0000-0003- $\underline{1887-098 X}$} \\ Fernando Fragozo

\section{André Mendonça \\ Professor Adjunto \\ Universidade do Estado \\ do Rio de Janeiro \\ alomendonça@gmail.com \\ http://orcid.org/0000-0002- $\underline{0077-3527}$}

Recebido em: 09/10/2020

Aceito em: 08/06/2021

\section{Resumo}

Para muitos povos tradicionais, a floresta não é apenas a materialidade formada pelo conjunto de árvores que a compõem: ela inclui também a essência viva dos seres que a habitam. Cada um desses seres (humanos, animais, plantas e, eventualmente, outros) possui sua própria perspectiva sobre a floresta e, por consequência, seu próprio espaço existencial. A proposta deste ensaio é a elaboração de um conceito de floresta segundo o qual a floresta não é apenas um objeto material, mas refere-se ao fora do próprio mundo, com o qual uma outra dinâmica que não a da predação possa ser estabelecida. Com esse objetivo em vista, em primeiro lugar, investiga-se o conceito de inimigo proposto por Eduardo Viveiros de Castro como contrapartida ao conceito de sujeito ocidental. Em seguida, analisa-se o conceito de limite, proposto por Alexandre Nodari, como contraposição ao conceito de espaço ocidental. Ao tensionar-se os conceitos de inimigo e limite, propõe-se o termo floresta para referir-se a outro modo de relação possível com a sociodiversidade de mundos humanos e a biodiversidade. Por fim, são apresentados os traços gerais da experiência de floresta, na floresta dos yanomami, a partir dos trabalhos de Bruce Albert, François-Michel Le Tourneau e Julia Verdum. Nas considerações finais discute-se a floresta como uma disposição espacial e modo de convívio capaz de "adiar o fim do mundo".

Palavras-chave: Floresta; Fora; Cidade; Espacialidade; Yanomami; Inimigo; Limite.

\section{Abstract}

For many indigenous peoples, the forest is not just the materiality formed by the set of trees that it's made up of: it also includes the living essence of the beings that live there. Each of these beings (humans, animals, plants and, included, others) have their own perspectives on the forest and, consequently, their own existential space. The purpose of this essay is to develop a concept of forest where the forest is not just a material object, but refers to the exterior of the human world itself, with which a dynamic other than exploitation can be established. With this objective in mind, firstly, the concept of enemy proposed by Eduardo Viveiros de Castro is investigated as a counterpart to the concept of the Western subject. Then, the concept of limit, proposed by Alexandre Nodari, is analyzed, as opposed to the concept of Western space. When questioning the concepts of enemy and limit, it is proposed that the term forest can be used to describe another possible relationship with the sociodiversity of human worlds and biodiversity. Finally, the main characteristics of the forest experience in the yanomami's forest are presented, based on the works of Bruce Albert, François-Michel Le Tourneau and Julia Verdum. In the final considerations, the forest is discussed as a spatial arrangement and a way of living capable of "postponing the end of the world".

Keywords: Forest; Exterior; City; Spaciality; Yanomami; Enemy; Limits. 
É possível estender-se em quase todas as direções, disseminar-se tanto no tempo quanto no espaço, sem contudo preencher o tempo e o espaço [...]. Mas há a ciência, sempre renovando e totalizando e preenchendo os buracos vazios deixados pelas redes, transformando-as em superfícies lisas e unidas, absolutamente universais.

(LATOUR, 2017 [1991], p. 116)

Enquanto os modernos ocupam o espaço, os não-modernos habitam em lugares movendo-se ao longo das linhas e fios que produzem o lugar.

(ESCOBAR, 2017, p. 87)

$\mathrm{Na}$ floresta, a ecologia somos nós, os humanos. Mas são também, tanto quanto nós, os xapiri, os animais, as árvores, os rios, os peixes, o céu, a chuva, o vento e o sol! É tudo o que veio à existência na floresta, longe dos brancos; tudo o que ainda não tem cerca. [...]

(KOPENAWA, 2015, p. 480)

\section{Introdução}

De acordo com Deborah Danowski e Eduardo Viveiros de Castro (2015, p. 11), no Ocidente, a partir dos anos '90 do século passado, a expressão "fim do mundo" passou a se referir às "transformações em curso do regime termodinâmico do planeta". Trata-se do novo regime climático que convenceu os geólogos em definir a nossa época como "Antropoceno", isto é, a época que coloca a humanidade como "um evento súbito e devastador na história do planeta" (DANOWSKI; VIVEIROS DE CASTRO, 2015, p. 27). Todavia, a partir da constatação de que, "para os povos nativos das Américas, o fim do mundo já aconteceu, cinco séculos atrás" (DANOWSKI; VIVEIROS DE CASTRO, 2015, p. 138), os autores põem em questão qual "humanidade" e qual "mundo" são esses que estão prestes a seus fins. A partir da convicção de que seja necessário especificar "quem está falando, quando se diz 'nós"' (DANOWSKI; VIVEIROS DE CASTRO, 2015, p. 33), os autores do presente trabalho se posicionam entre aqueles para quem o fim do mundo está acontecendo apenas agora, isto é, os "brancos", no sentido que Viveiros de Castro deu a esse termo ${ }^{1}$. O questionamento proposto, longe de negar que as condições biogeofísicas da Terra estejam tornando-se inabitáveis para muitos seres viventes - dentre os quais, os seres humanos - abre margem para criticar as soluções propostas no Ocidente para lidar com o Antropoceno.

A partir da análise do texto de Dipesh Chakrabarty (2013, p. 22), no qual o historiador indiano coloca a "humanidade" como agente único da "história universal negativa", Danowski e Viveiros de Castro concluem, em primeiro lugar, que o fim do mundo não é causado pela humanidade como uma totalidade, mas sim pelo sistema econômico daqueles Estados Nacionais ocidentais que fazem parte da "civilização global" (CHAKRABARTY, 2013, p. 20)².

1 "Isto é, os membros (de qualquer cor) daquelas sociedades nacionais que destruíram a autonomia política e a suficiência econômica do povo nativo de referência" (VIVEIROS DE CASTRO, 2015, p. 12). Com essa nomenclatura nos referimos ao texto "O recado da mata" escrito por Eduardo Viveiros de Castro como prefácio à edição portuguesa do livro "A queda do céu” de Davi Kopenawa e Bruce Albert (2015).

2 Para uma discussão mais ampla sobre as problemáticas relacionadas ao termo Antropoceno, sugere-se a leitura do texto The Capitalocene, obra mais recente de Jason Moore (2017). 
Em segundo lugar, a partir do conceito de perspectivismo, Danowski e Viveiros de Castro (2015) argumentam que o mundo não é apenas um: o mundo criado pela civilização global e responsável pelo "fim do mundo" é apenas um dos mundos possíveis. Nesse caso, o reconhecimento da existência de povos que tradicionalmente habitam a Terra sem devastá-la, isto é, de seres humanos que não fazem parte da "humanidade negativa" proposta por Chakrabarty (2013), leva os autores (CHAKRABARTY, 2013, p. 159) a considerar um novo caminho para solucionar o problema denominado "fim do mundo" no Ocidente, a saber, o de levar a sério o pensamento indígena ${ }^{3}$. A proposta de levar a sério o pensamento indígena pode ser interpretada como a possibilidade de aprender desses povos "figuraç[ões] de futuro" a partir da "bricolagem tecnoprimitivista" (CHAKRABARTY, 2013) praticada por eles. Mas, no que consiste essa tecnologia primitiva capaz de "adiar o fim do mundo" (KRENAK, 2019)?

Como já apontado várias vezes por Viveiros de Castro ${ }^{4}$, é suficiente olhar para qualquer imagem de satélite de qualquer uma das terras indígenas brasileiras, para se dar conta de que os povos indígenas vivem com a floresta sem devastá-la. Assim, a existência de povos que tradicionalmente habitam a floresta é uma prova empírica de que a vida do ser humano não é ligada a priori à devastação do planeta Terra. Com isso, neste trabalho, argumenta-se que a devastação do ecossistema não é uma necessidade biológica de nenhuma espécie vivente presente na Terra, mas sim uma necessidade criada pelo modo de entendimento do real e pela disposição espacial do ser humano ocidental e de suas cidades. Mais especificamente, as cidades ocidentais são consideradas, neste ensaio, como o resultado entrópico de uma noção espacial egocentrada.

Com o objetivo de pensar uma alternativa a essa experiência de cidade ocidental, a presente argumentação se estrutura em cinco seções. Em primeiro lugar, investiga-se o conceito de inimigo, proposto por Eduardo Viveiros de Castro (1992, 2002, 2018), como contrapartida ao conceito de sujeito ocidental. Em segundo lugar, analisa-se o conceito de limite, proposto por Alexandre Nodari (2019), como contraposição ao conceito de espaço ocidental. Em terceiro lugar, tencionam-se os conceitos de inimigo e limite e propõe-se o termo floresta para referir-se ao contra-urbanismo dos povos ameríndios. Em quarto lugar, verifica-se o conceito de floresta no caso de estudo da floresta dos yanomami, a partir dos trabalhos de Bruce Albert (2007), François-Michel Le Tourneau (2007) e Julia Verdum (2014). Enfim, nas considerações finais discute-se a floresta como uma disposição espacial capaz de "adiar o fim do mundo" (KRENAK, 2019) por meio de seu projeto neguentrópico (VALENTIM, 2018a; 2018b).

\section{Inimigo enquanto um eu-como-outro: o antinarcisismo dos ameríndios}

Viveiros de Castro, em seu texto From the Enemy's point of view de 1992, se depara com a presença, na cultura Araweté ${ }^{5}$ de um pronome pessoal inexistente em nossa cultura ocidental. Esse pronome é, em araweté, awï, que, da mesma forma que bïde, refere-se à primeira pessoa do singular: Eu. Em outras palavras, na cultura Araweté existem dois modos para referir-se ao sujeito ontológico. Para o antropólogo brasileiro, a diferença entre bïde e awï reside no fato de que, enquanto bïde é Eu na forma de idêntico a mim, awï refere-se a Eu na forma de diferente de mim, isto é, de outro com relação ao Eu que o pronuncia (VIVEIROS DE CASTRO, 1992, p. 64-65).

3 Segundo os autores (DANOWSKI; VIVEIROS DE CASTRO, p. 34) a visão ocidental de uma única humanidade como agente devastador, traz apenas duas conclusões possíveis. A primeira é de um "mundo sem nós", ou seja, um mundo danificado que não abriga mais os seres humanos. A segunda é de um "nós sem mundo", isto é, uma humanidade cósmica libertada de seus vínculos terrenos - ou por meio de uma antropização total do planeta Terra ou por meio da construção de uma nave espacial. Nesse sentido, a proposta de levar a sério o pensamento indígena, isto é, de "um mundo de gente" (DANOWSKI; VIVEIROS DE CASTRO, p. 85), põe-se como uma opção à visão mainstream ocidental.

4 Ver, por exemplo, o discurso proferido por Eduardo Viveiros de Castro, durante a palestra inaugural do curso "Desastres e mudanças climáticas: Construindo uma agenda", que ocorreu no Rio de Janeiro, no dia 12 de agosto 2019, no Colégio de Altos Estudos da Universidade Federal do Rio de Janeiro (disponível em: www.youtube.com/watch?v=T0smbaZ4NCs). Os Araweté são um povo Tupi-Guarani do leste da Amazônia (Médio Xingu, Brasil). 
Em razão do fato de que seu uso é predominante na designação dos sujeitos com os quais os Araweté entretêm relações de inimizade, o autor propõe traduzir awï com o termo Inimigo. Todavia, o conceito de guerra de vingança dos Araweté é muito diferente de nossa concepção de guerra e, por isso, awï tem que ser cuidadosamente distinguido do conceito ocidental de inimigo. Como afirma o autor (VIVEIROS DE CASTRO, 1992, p. 254), a guerra de vingança Araweté, cujo clímax termina com a cerimônia de canibalismo do inimigo (awï), não é, como o observador ocidental poderia supor, o momento do aniquilamento da alteridade. Pelo contrário, segundo o antropólogo, a guerra de vingança Araweté consiste em um sofisticado sistema de troca de "capital ontológico" (VIVEIROS DE CASTRO, 2002, p. 284) por meio da introjeção da captura e integração na comunidade de um guerreiro de outra aldeia: o inimigo $a w i^{6}$. Além disso, vale a pena lembrar que, para os Araweté, o Eu não é uma posição exclusivamente antropomorfa (VIVEIROS DE CASTRO, 1992, p. 69). Nesse sentido, o inimigo pode ser tanto humano, quanto animal ou vegetal.

Assim, a tradução de awï como inimigo deve levar em conta uma inversão de polaridade do termo: enquanto, para nós, ocidentais, o inimigo é um elemento negativo, para os Araweté o inimigo é o motor da construção da subjetividade e do tempo histórico coletivo. Nesse sentido, para os povos ameríndios o inimigo não é o oposto antagônico do Eu, mas o próprio devir possível de sua essência. Nos termos do autor,

em lugar de aparecer como termo de uma estrutura que se desdobra ou explica em pólos opostos, ego e inimigo, essa entidade 'monopolar' que é o matador constitui-se por involução ou implicação, determinando-se como foco virtual de uma condensação predicativa onde a dupla negação - eu sou inimigo de meu inimigo - não restitui uma identidade que já estaria lá como princípio e finalidade, mas, ao contrário, reafirma a diferença e a faz imanente - eu tenho um inimigo, e por isso o sou. Ou o Eu o é. A agressão guerreira ameríndia revela-se então um processo de "transformação ritual do Eu" (VIVEIROS DE CASTRO, 2002, p. 293).

Em outras palavras, o Inimigo não é a negação do Eu. O Inimigo é o Eu, expresso pela alteridade contida na imagem do Outro: Eu sou o Outro dos outros. Mas, o que significa que o inimigo é Eu em forma de Outro? Segundo Viveiros de Castro, em seu texto Metafísicas Canibais de 2018, para compreender a fundo o conceito de inimigo ameríndio é preciso recorrer à distinção entre dois tipos de imagem do Outro. Nas palavras do autor,

uma expressão prototípica de Outrem da tradição ocidental é a figura do Amigo. O Amigo é outrem, mas outrem como "momento" do Eu. Se me determinam como amigo do amigo, é apenas porque o amigo, na conhecida definição de Aristóteles, é um outro Eu mesmo. O Eu está lá desde o início: o amigo é a condição-Outrem pensada retroprojetivamente sob a forma condicionada do sujeito. [...] O amigo é, em suma, [...] uma personagem conceitual, o esquematismo de Outrem do próprio conceito. A filosofia exige o Amigo, a philia é o elemento do saber (VIVEIROS DE CASTRO, 2018, p. 225-226).

Com isso, o autor conclui que, se o sujeito do pensamento ocidental é o "idêntico ao Eu", na cultura ocidental, toda e qualquer representação de um outro sujeito pensante é aprisionada na ideia de "Outro" como "Mesmo" (VIVEIROS DE CASTRO, 2018, p. 21). Essa constatação leva o autor a associar o conceito de sujeito ocidental com a personagem mítica do Narciso, um homem capaz de amar apenas a si mesmo. Como argumenta Juliana Fausto (2017),

6 Resumidamente: o inimigo Araweté, uma vez introduzido na aldeia como cativo é, logo em seguida, transformado em "cunhado" do guerreiro Araweté que o capturou e tratado como um membro da comunidade. O inimigo, engravidando a irmã de seu futuro matador, gera os futuros membros do povo Araweté. Além disso, o inimigo dá nomes e anuncia histórias de sua comunidade de origem para os membros da comunidade Araweté. Ao final desse período, que pode durar anos, o inimigo é morto pelo guerreiro que o capturou e comido pelos outros membros do grupo. Antes de morrer, o inimigo e o matador entretém um diálogo público durante o qual o cativo lembra todos os nomes dos guerreiros Araweté mortos por mão da comunidade de origem do cativo e promete vingança futura por parte dos seus. Sobre o rito canibal Araweté ver: Viveiros de Castro (1992, p. 273-301). 


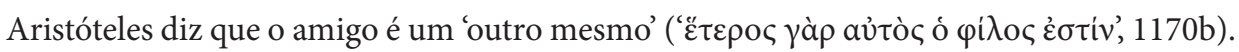
[...] Héteros [...] é uma palavra que significa diferente em um contexto binário (por exemplo, quando se diz, em grego, 'a outra mão' para designar a mão esquerda), ao contrário de állos, que quer dizer qualquer outro. $\mathrm{O}$ amigo, então, como héteros autós é uma espécie de parte constitutiva ou ligada ao mesmo (eu), aquele a partir de quem o mesmo é. A filosofia, que traz o amigo em seu próprio nome [...] excluiria[...] assim todos os 'quaisquer outros' - tudo aquilo que, [...] para Aristóteles, constituem inimigos ou outros não binários. Não são só os animais que estariam fora da política, mas todos os outros fora de relações de par, todos os que não são meus amigos. (FAUSTO, 2017, p. 45-46).

Em contraposição à imagem do Outro ocidental, o antropólogo brasileiro propõe que o sujeito ameríndio seria, então, o anti-Narciso:

o problema liminar colocado por qualquer tentativa de identificar o equivalente ameríndio para "nossa" filosofia é de pensar o mundo constituído pelo Inimigo enquanto determinação transcendental. Não o amigo-rival da filosofia grega mas a imanência do inimigo da cosmopráxis ameríndia, onde a inimizade não é um mero complemento privativo da amizade, [...] mas uma estrutura de direito do pensamento, que define uma outra relação com o saber e um outro regime de verdade (VIVEIROS DE CASTRO, 2018, p. 226).

Se o conceito de Outro ameríndio não tem nada a ver com o Mesmo, o inimigo Araweté seria então um sujeito pensante, da mesma ordem ontológica do Eu, mas cujo pensamento é diferente do meu. Dessa perspectiva, o conceito de inimigo proposto por Viveiros de Castro $(1992,2002,2018)$ corresponde a um Eu-como-outro e não um outro-como-Eu. Isso implica uma conclusão paradoxal aos olhos ocidentais: a de que outros seres, diferentes do Eu, pensam e existem, e não porque eles sejam como Eu, mas pelo contrário, porque são diferentes de mim.

\section{Limite do conceito de "limite": a incorporação antropofágica do diferente}

A partir da distinção, proposta por Oswald de Andrade, entre consumo métrico - o consumo ocidental que esvazia de sentido o que consome - e o consumo antropofágico ${ }^{7}$, consumo dos povos ameríndios que adiciona sentido ao que consome -, Nodari (2019) propõe a distinção entre dois conceitos de limite. Segundo Nodari (2019, p. 83, grifo nosso), o conceito de limite ocidental é um "limite contorno, externo e transcendente, como forma que limita os corpos e impede a sua interpenetrabilidade, marcando uma extensão, e cujo movimento é do 'contentor ao conteúdo, da circunferência ao centro'”. Todavia, continua o autor, o limite contorno é apenas uma ilusão e "a transgressão da lei está [assim] contida na própria lei, o estabelecimento de um limite instaura uma dialética com o ilimitado, no qual o ultrapassamento da lei a confirma e a reforça” (NODARI, 2019, p. 72). Sob uma perspectiva dialética, Nodari (2019) propõe o limite-dinâmico da antropofagia ameríndia como o oposto dessa concepção ocidental de limite. Nos termos do autor,

o limite-dinâmico, interno e imanente [...] é a tensão dos corpos, a sua tendência, a sua inclinação, e, portanto, é intensivo e [...] não chega a uma circunferência extensa determinada, mas é um movimento de contração-dilatação a partir de um centro. De um lado, a forma que informa o corpo que tem lugar nesse limite; de outro, a força, a tensão do corpo que se expressa não por um contorno, mas por uma maneira de ser, de tender, por um modo (de vida), um hábito: não um lugar determinado, mas uma maneira de habitar o mundo, uma posição relacional. (NODARI, 2019, p. 83-84).

7 A mesma inversão de polaridade que adoptamos para o conceito de Inimigo de Viveiros de Castro é empregada para o conceito de Antropofagia de Oswald de Andrade. 
Figura 1: Limite contorno e limite-dinâmico

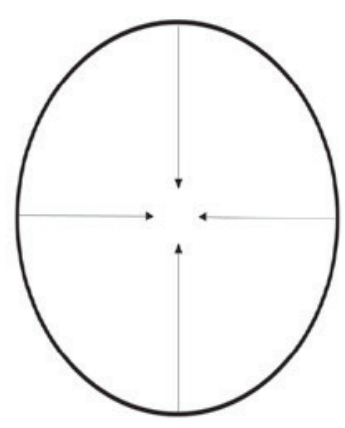

limite contorno

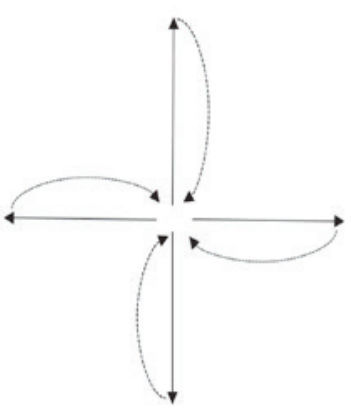

limite-dinâmico

Fonte: Desenhos elaborados por Alexandre Nodari (2019, p. 83).

Com base na distinção entre limite contorno e limite-dinâmico, o autor propõe "uma experiência-limite do limite" (NODARI, 2019, p. 93) que pode ser entendida como o consumo antropofágico do limite contorno por parte do limite-dinâmico. Essa dinâmica de incorporação do diferente é típica da antropofagia ameríndia e é caracterizada pelo contato entre o que está dentro do limite com o que ficou do lado de fora:

Daí o sentido profundo de um trecho do Manifesto Antropófago: "Da equação eu parte do Cosmos ao axioma Cosmos parte do eu. Subsistência. Conhecimento. Antropofagia”. Pois tratava-se de transformar um regime no qual o eu é uma porção delimitada do mundo, uma extensão, em outro no qual o mundo é o efeito da com-posição de sujeitos e suas intensidades, uma circunferência (inexistente) que resulta das (in)tensões combinadas de cada eu, da interpenetração dos corpos que os limites-contorno impediam. Isso que Oswald chamava de subsistência antropofágica era, portanto, um contato com a exterioridade: "O cosmos parte do eu", mas “Só me interessa o que não é meu”. Dito de outro modo, o mundo não existe, mas subsiste: é aquilo que está entre os seres, o interesse, a resultante de suas transformações recíprocas, o efeito de suas devorações. Só me interessa o que não é meu, ou seja, só me interessa o mundo - que parte de mim (NODARI, 2019, p. 87).

A proposta de Limitar o limite de Nodari (2019) não deve ser confundida com a "mera transgressão" (NODARI, 2019, p. 72) do limite entre verdadeiro/falso, justo/injusto, lei/fora-da-lei, obediência/transgressão. Partindo da lógica situacionista do "é proibido proibir", o autor afirma que o que está em jogo é "o acesso a outra configuração da vida para além (ou aquém) dessa lógica da lei, e, portanto, uma outra economia dos possíveis" (NODARI, 2019, p. 73). Em outras palavras, enquanto o limite contorno consiste na separação radical entre o interno e o externo - e no anulamento desse último em favor do primeiro -, o limite-dinâmico baseia-se no contato com a exterioridade. Assim, se o limite contorno ignora tudo o que está fora de seu limite, o limite-dinâmico proporciona uma diversidade de corpos externos ao limite. A partir dessa constatação, o autor conclui que é preciso estimular outros modos de habitar o mundo (NODARI, 2019, p. 94-95). Nos termos do autor,

a guerra do Antropoceno [...] é uma guerra entre hábitos, i.e., entre formas de habitar o mundo, ou melhor, entre modos de modos de vida: aqueles hábitos codificados na lei que barra os possíveis pela "estandardização do homo sapiens" [...], e aqueles hábitos contra a lei, hábitos de subsistência, modos de habitar o mundo que sustentam ao máximo os possíveis que adubam a existência. (NODARI, 2019, p. 94-95) 


\section{Esboço do conceito de floresta}

Com base no conceito de Inimigo, Viveiros de Castro constata que o conceito de mundo dos povos indígenas da América Latina não pode ser o mesmo que o nosso: enquanto para os ocidentais o mundo é um espaço único habitado pelo amigo, para os ameríndios é um pluriverso formado pela soma das perspectivas de cada inimigo. Nesse sentido, o autor propõe o termo "multinaturalismo perspectivista" para se referir ao fato que "os ameríndios propõem [...] uma unidade representativa ou fenomenológica puramente pronominal, aplicada indiferentemente sobre uma diversidade real" (VIVEIROS DE CASTRO, 2002, p. 379). Em outras palavras, o sujeito ocidental com seus amigos, não enxergando outro ser pensante fora de si próprio, não vê outro mundo a não ser o que o seu ponto de vista oferece. Enquanto isso, o conceito de inimigo propõe que cada ser (humano, animal, planta) possui seu próprio pensamento radicalmente diferente e enxerga o próprio mundo como apenas um dos mundos que existem no planeta Terra.

Contudo, cabe investigar: Como é possível que vários mundos caibam no mesmo espaço, que nós chamamos de Terra? Um caminho para responder a essa pergunta é ressignificar o nosso conceito de espaço, a partir da distinção entre os dois conceitos de limite propostos por Nodari (2019).

Gostaríamos de ressaltar que, enquanto no limite contorno, o espaço é a superfície delimitada pelo círculo, no limite-dinâmico o espaço é apenas a linha que tende ao externo (Figura 1). Assim, com base nos conceitos de limite contorno e limite-dinâmico é possível derivar dois diferentes conceitos de espaço: por um lado, o limite contorno proporciona um espaço plano que ocupa por inteiro o território no qual é aplicado; por outro lado, o limite-dinâmico é um espaço linear que ocupa apenas a sutil porção de território na qual insistem suas linhas. Desse modo, enquanto no limite contorno não há espaço para outras espacialidades, no limite-dinâmico outras dimensões cabem ao lado do espaço linear formado pelas linhas de fuga dos corpos ${ }^{8}$.

Todavia, nenhum sistema é fechado em si mesmo. Por exemplo, ao analisar o mundo ocidental, Almeida afirma que,

não há no mundo real capitalista reprodução e muito menos acumulação capitalista harmoniosa e auto-sustendada. O que há [...] é sempre expansão desequilibrada, caótica e predatória. A predação consiste no fato de que [...] o centro formado pelo modo de produção capitalista se alimenta necessáriamente de uma periferia constituída por inúmeros regimes não-capitalistas - relação essa de incorporação predatória porque destrói aquilo de que se alimenta como condição de sua vitalidade. Essa periferia é apropriada e destruída ao se converter em mercados consumidores, e em fonte de recursos e matérias-prima. (ALMEIDA, 2012, p. 5) ${ }^{9}$

Assim, temos sempre que imaginar tanto o espaço plano quanto o espaço linear, não como sistemas estáveis mas sim como sistemas em contínua expansão. Com base na segunda lei da termodinâmica proposta por Carnot, Almeida (2016, p. 28) conclui que o movimento centro/periferia do mundo ocidental é um movimento entrópico porque "transforma energia rica em diversidade em energia com baixa diversidade". Contrariamente ao sistema cêntrico ocidental, Almeida (2012, p. 6-7) propõe o termo "sociodiversidade" para se referir aos "exemplos de modos alternativos de vida social oferecidos pela diversidade de povos indígenas, de povos afrodescendentes, de povos mestiços-camponeses". Esses exemplos apontam para sistemas de "reservas de diferença” por meio do uso localizado da floresta em pé, ao invés do movimento entrópico centro/

8 Nodari (2019) representa graficamente o limite-dinâmico por meio de quatro flechas que, a partir de um centro comum, estendem-se e comprimem-se em quatro direções diferentes (figura 1, à esquerda). Contudo, acreditamos que, ao lado das flechas quadri-direcionais desenhadas por Nodari (2019) - que podem ser interpretadas como a perspectiva espacial de um ser específico - é preciso imaginar indefinidas outras flechas espaciais dos outros seres que habitam o mesmo território.

9 Seria aqui preciso enfatizar que não se trata apenas do capitalismo mas de toda a vertente de pensamento que se desdobra a partir do século XIX na Europa Ocidental em torno dos conceitos de "acumulação", "progresso" e "desenvolvimento". Nesse sentido, as vertentes do socialismo que não colocam em questão a relação com a socio e/ou a biodiversidade, e não questionam a industrialização sem limites, também precisam ser incluídas nessa reflexão. 
periferia. Em outros termos, enquanto a expansão do espaço plano proporciona a devastação da diferença, a expansão do espaço linear mantém inalterada a biodiversidade das espacialidades exteriores.

O que, a rigor, significa que, sob esse modelo de expansão, existe uma estreita relação entre destruição da sociodiversidade (diferentes modos de o humano viver) e da biodiversidade (diferentes modos de vida biológica). Em outras palavras, como sintetizou Valentim (2018b, p. 72), a neguentropia ${ }^{10}$ do ecossistema terrestre é devorada pelos agentes do Antropoceno: "Plantas, animais e escravos humanos' são literalmente consumidos 'para aumentar a energia disponível para classes dominantes e sustentar cidades e impérios".

Segundo Nodari (2015), "enquanto dentro dos muros da cidade, o homem é como um Deus para o homem [...] e o cidadão reconhece a si mesmo no outro, fora deles, na relação entre cidades [...] o homem é o lobo do homem (homo homini lupus) - e o que está fora dos muros da cidade é justamente a floresta (fòris - o que está fora dos portões)". Assim, o autor conclui que "a floresta apresenta-se [...] como exterioridade à cidade (Estado)" (idem). A partir desse desdobramento, nota-se uma afinidade entre os conceitos de limite contorno e cidade ocidental - bem como entre limite-dinâmico e floresta.

Frente às questões até aqui apresentadas, o presente trabalho propõe adotar o conceito de cidade como a disposição de pensamento que se desdobra em disposição espacial consequente ao limite contorno, e o conceito de floresta, como o local de pensamento do múltiplo simultâneo, que se desdobra espacialmente na convivência minimamente respeitosa de outros modos de ser no âmbito do limite-dinâmico. Enquanto na cidade cabe apenas o mundo dos seres humanos, muitos mundos distintos cabem entre as linhas da floresta (superfície desenhada esquematicamente em cinza na Figura 2). Além disso, enquanto a cidade olha para os outros espaços de "fora" como estoque de energia morta ou instrumento (minérios, árvores abatidas, animais mortos, mão-de-obra etc.), o conceito de floresta emprega a energia disponível da mata em pé para a preservação comum da bio e sociodiversidades contemporâneas.

Como se vê, floresta, aqui, tem simultaneamente o sentido abstrato de uma reserva de modos de ser e o sentido concreto referente ao local de vida biológica plural. Metáfora abstrata da floresta real, o conceito de floresta pretende apontar para a existência real desse "fora" que é o radicalmente outro em termos de vida, existência, localização e modo de ser. E se a floresta conceitual se apresenta como esse espaço outro que não é da ordem do mesmo, o que está em jogo nesse reconhecimento é o do respeito a outro modo de ser e a busca de uma convivência mínima que não destrua o que está "fora": sociodiversidade ou biodiversidade, esta última pensada como floresta real, efetiva, amazônica ou outra, mas também como mangues, pântanos, geleiras, mares, savanas ou mesmo desertos e outros, na medida em que haja ecossistemas a serem respeitados.

Assim, se, por um lado, o crescimento da cidade, como conceito e estruturação efetiva espacial, é um sistema aniquilador de mundos, por outro, a expansão da floresta, como conceito outro e estruturação espacial outra, poderia permitir a convivência entre mundos diferentes ou divergentes entre si (Figura 2). Para ilustrar essa hipótese propõe-se analisar o caso da floresta dos yanomami do Brasil.

10 A entropia (do grego antigo èn+tropé, "em direção à agitação" ou "em direção à mudança") é um conceito da termofísica que indica a mudança de um estado inicial ordenado para um estado final de desordem. Essa mudança acarreta, devido a agitação das partículas, o aumento de temperatura. A negentropia (ou entropia negativa) é um termo cunhado por Erwin Schrödinger para se referir à vida no planeta Terra como um sistema que operou em direção oposta à tendência universal entrópica. Resumidamente, é como se a fauna e a flora terrestre foram capazes de manter um determinado ecossistema por um tempo maior do que aconteceria se a Terra fosse privada delas. 
Figura 2: Floresta e cidade.
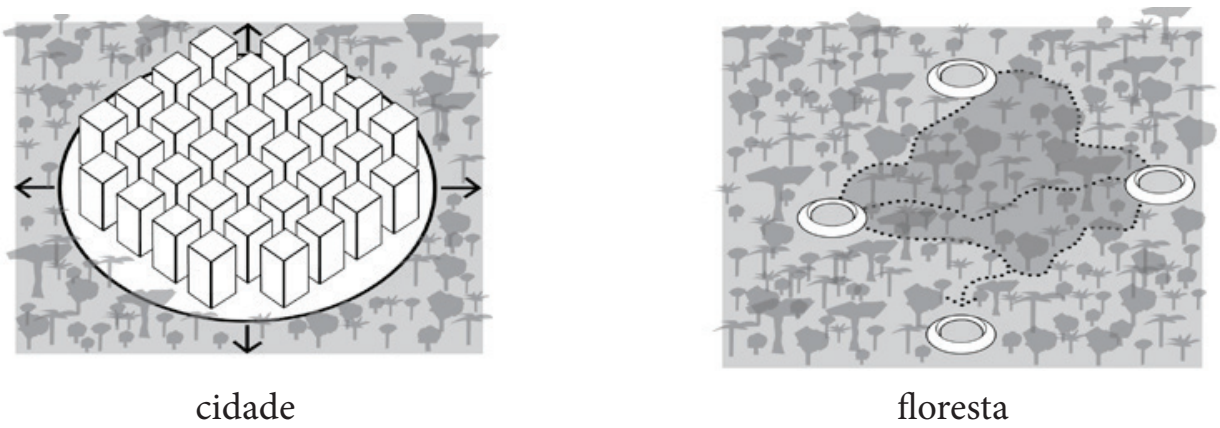

Fonte: Elaboração dos autores.

\section{A floresta dos yanomami}

Os yanomami do Brasil constituem um grupo indígena de aproximadamente 21 mil pessoas que ocupa um território de 96.650 quilômetros quadrados (KOPENAWA; ALBERT, 2015, p. 560). Esse grupo é composto por cerca de 260 sub-grupos locais (ou aldeias) distintas (KOPENAWA; ALBERT, 2015, p. 565). Conforme examina Verdum (2014),

[essas] comunidades mantêm relações de troca matrimonial, cerimonial e econômica entre os vários grupos locais circunvizinhos, formando conjuntos multi-comunitários de aliança que se superpõem parcialmente e, gradativamente, vão formando uma rede sociopolítica ampla e complexa que liga as aldeias Yanomami de uma ponta à outra do território indígena. (VERDUM, 2014, p. 36).

De acordo com Bruce Albert e François-Michel Le Tourneau (2007), os estudos antropológicos clássicos sobre o uso do espaço na floresta Amazônica nunca levaram realmente em consideração os padrões espaciais do uso dos recursos naturais da floresta dos Yanomami. Com o objetivo de superar essa visão que "projeta nas atividades produtivas Yanomami uma concepção etnocêntrica de 'anéis' sucessivos" (ALBERT; LE TOURNEAU, 2007, p. 583, tradução nossa), os antropólogos franceses propuseram uma metodologia de análise que leva em consideração as áreas florestais além das redondezas imediatas da aldeia singular de cada grupo indígena. Nos termos dos autores, "sob essa nova perspectiva, a organização etno-geográfica do espaço Yanomami parece ser reticular - estruturada por uma rede cruzada de locais (pontos) e rotas (linhas) - em vez de zonal" (ALBERT; LE TOURNEAU, 2007, p. 584). Em outras palavras, para Albert e Le Tourneau (2007) é impossível delimitar o uso do espaço Yanomami à mera aldeia ou à clareira em volta da aldeia. É preciso considerar também a "estrutura reticular de teias cruzadas de caminhos nomeados e locais espalhados pela casa coletiva e sua área de jardim” (ALBERT; LE TOURNEAU, 2007, p. 585). Esses caminhos abrangem, além das áreas de coleta mais distantes da aldeia, também os espaços florestais necessários para se conectar com outras aldeias de grupos aliados.

Tanto Albert e Le Tourneau (2007) quanto Verdum (2014) parecem apontar para uma reavaliação do papel social dos caminhos utilizados pelos Yanomami, passando a considerá-los como o lugar de história coletiva. Nas palavras de Verdum,

através desta rede de caminhos, que se espalha por todo o território e liga lugares conhecidos e nomeados, geossímbolos prenhes de sentidos, se realiza a produção do espaço e das territorialidades. É no caminhar e no dar sentido que os yanomami vão grafando seu mundo [...] Os nomes dos lugares são usados principalmente na tradução oral, sendo os guardiões da memória e os pontos de ancoragem da história (VERDUM, 2014, p. 52). 
Um dos fatores-chave que confirma que o espaço em questão seja um espaço reticular é, para Albert e Le Tourneau (2007), a existência na cultura Yanomami de um espaço "negativo" da rede, isto é, porções de espaço que se formam entre as trilhas, e que os Yanomami chamam de "floresta fechada" (em yanomami, urihi komi). Esses espaços são considerados espaços espectrais e, portanto, perigosos para os Yanomami. Nas palavras dos autores,

\begin{abstract}
esses espaços são essencialmente definidos pela ausência de qualquer experiência humana permanente e pela possibilidade de maus encontros com "espíritos da floresta" [...]. Como "zonas vazias" de floresta não explorada deixada dentro ou fora das redes de rotas de caça, coleta e viagem, elas provavelmente desempenham um papel ecológico significativo como áreas de refúgio de caça. [...] O fato de essa organização espacial incluir zonas vazias culturalmente reconhecidas como "floresta fechada" confirma ainda mais que estamos testemunhando um sistema reticular, uma vez que essa estrutura de pontos e linhas em rede nunca preenche completamente o espaço pelo qual se espalha (ALBERT; LE TOURNEAU, 2007, p. 589).
\end{abstract}

Se, por um lado, a rede dos caminhos abrange toda a terra yanomami, por outro, essa rede nunca preenche completamente o espaço. Segundo Verdum (2014, p. 43), “o que ocorre é que, altamente sábios e conhecedores da dinâmica da floresta, os Yanomami desenvolveram um sistema social, político e econômico que privilegia a dispersão territorial, uma vez que a concentração demográfica levaria inevitavelmente ao esgotamento dos recursos". Em outros termos, os espaços urihi komi são reservatórios de biodiversidade situado no meio do espaço vivido pelos yanomami. Além disso, esses espaços têm também o papel de respeito da diversidade ontológica, uma vez que os espaços denominados de "floresta fechada" (urihi komi) são espaços fora do controle yanomami, onde outros seres da floresta têm a possibilidade de viver e criar suas redes outras-que-yanomami.

Em suma, o espaço criado pelos yanomami não é apenas um conjunto de pontos separados no território à modo do policentrismo urbano. Estamos frente a uma espacialidade realmente inédita no panorama da arquitetura e do urbanismo ocidental, onde a floresta fechada é o verdadeiro centro, em volta do qual se tece a rede dos caminhos vividos pelos yanomami. Em outras palavras, urihi, a floresta dos yanomami, é um arquipélago de florestas, cujas beiras são habitadas pelos yanomami e não apenas um conjunto de aldeias interligadas por caminhos.

\title{
Considerações finais
}

A partir da contraposição feita por Davi Kopenawa (2015), entre a floresta dos yanomami e a cidade dos brancos, Valentim (2018a, p. 162) afirma que,

enquanto a filosofia transcendental procura estabelecer limites e fronteiras, circunscrevendo uma esfera de sentido exclusivamente humana - a cidade cosmopolita -, o pensamento xamânico realiza uma 'comunicação entre incomunicáveis', abrindo uma 'zona transespecífica' de contágio entre humanos e extra humanos - a 'terra-floresta' (urihi a).

Em outros termos, segundo o autor, a exclusão da "extramundanidade" e da "sobrenatureza" é a origem da devastação da floresta por parte da cidade. Nesse sentido, segundo o filósofo brasileiro o tema da aniquilação ontológica liga-se ao tema da devastação ambiental. Nos termos do autor,

"essa entropia", antrópica, que "levará inexoravelmente a sociedade e o universo de volta ao caos pré-humano", deve-se ao "resultado do excesso de poder predatório da alteridade branca" [...] e não a uma suposta "vocação ecocida congênita do Homo sapiens" [...]. 
Se é verdade que "a entropia crescente se transfigura dialeticamente em antropia triunfante" [...], esta é, da floresta à cidade, contraefetuada distopicamente por aquela. (VALENTIM, 2018a, p. 196) ${ }^{11}$

De forma parecida, Ailton Krenak (2019, p. 46-47), afirma que "se nós imprimimos no planeta Terra uma marca tão pesada é por[que] excluímos da vida, localmente, as formas de organização que não estão integradas ao mundo da mercadoria, pondo em risco todas as outras formas de viver". Com isso, se o mundo ocidental está prestes a seu fim, não é porque a humanidade como um todo é destinada a devastar o ambiente na qual vive, mas sim porque os povos ocidentais (e nós acrescentaríamos, os "ocidentalizados") desconsideraram os mundos daqueles outros seres que habitam a Terra. Nos termos do autor: "quando despersonalizamos o rio, a montanha, quando tiramos deles os seus sentidos, considerando que isso é atributo exclusivamente dos humanos, nós liberamos esses lugares para que se tornem resíduos da atividade industrial e extrativista" (KRENAK, 2019, p. 49).

Se o fim do mundo não é causado pela "humanidade negativa" proposta por Chakrabarty (2012), mas sim por uma pequena porção de indivíduos, há então uma possibilidade de adiar o fim do mundo. A partir da constatação de que o fim do mundo em curso é apenas o fim do mundo ocidental, Krenak (2019, p. 57) propõe abraçar a ideia do fim de mundo como uma possibilidade para imaginar novos mundos. Nesse sentido, o conceito de floresta pode ser uma disposição espacial capaz de adiar o fim do mundo.

\section{Referências}

ALBERT, Bruce; LE TOURNEAU, François-Michel. Ethnogeography and Resource Use among the Yanomami: Toward a Model of "Reticular Space". Current Anthropology, University of Chicago Press. 48 (4). P. 584-592. Chicago: 2007

ALMEIDA, Mario William Barbosa. Sociodiversidade e desenvolvimento. Considerações entre centro e margem. 2012 Disponível em: <www.academia.edu/42120654/Sociodiversidade_e_desenvolvimento_Considera\%C3\%A7\%C3\%B5es_entre_centro_e_margem> Acesso em: 25 maio 2021.

ALMEIDA, Mario William Barbosa. Desenvolvimento entrópico e a alternativa da diversidade. Revista Ruris. Volume 10 n. 1. Março, 2016

CHAKRABARTY, Dipesh. O clima da história: quatro teses. Sopro. Florianópolis: Cultura e Barbárie. Volume 91. P. 2-22. Julho, 2013.

DANOWSKI, Déborah. VIVEIROS DE CASTRO, Eduardo. Há mundo por vir? Ensaios sobre os medos e os fins. Florianópolis: Cultura e Barbárie. 2015.

ESCOBAR, Arturo. Designs for the Pluriverse: Radical Interdependence, Autonomy, and the Making of Worlds. Duke University Press. Durham and London: 2017

KRENAK, Ailton. Ideias para adiar o fim do mundo. Companhia das letras. São Paulo: 2019

KOPENAWA, Davi. ALBERT, Bruce. A queda do céu: Palavras de um xamã Yanomami. São Paulo: Companhia das letras, 2015. [2010]

LATOUR, Bruno. Jamais fomos modernos. São Paulo: Editora 34, 2016

MOORE, Jason W. The Capitalocene, Part I: on the nature and origins of our ecological crisis. The Journal of Peasant Studies. Londres: Taylor \& Francis Online. Volume 44. P. 594-630. Março, 2017.

NODARI, Alexandre. "Selva de pedra"? A floresta e a cidade. Partes sem um todo. 2015 Disponivel em: <partessemumtodo.wordpress.com/2015/07/09/selva-de-pedra-a-floresta-e-a-cidade> Acesso em: 22 fev 2021.

NODARI, Alexandre. Limitar o limite: modos de subsistência. Ilha Revista de Antropologia. Florianopolis, v. 21, n. 1, p. 68-72, junho de 2019.

VALENTIM, Marco Antonio. Extramundanidade e sobrenatureza: Ensaios de ontologia infundamental. Florianopolis: Cultura e Barbarie, 2018a.

11 Ver nota 1 quanto ao conceito de "branco". 
VALENTIM, Marco Antonio. Fascismo, a política oficial do Antropoceno. IHU On-line. Revista do Instituto Humanitas Unisinos, ano XVIII, n. 531, 17/12/2018, p. 70-75. 2018b

VERDUM, Julia Selau. Quando os habitantes da Montanha do Vento grafam seu mundo. Dissertação [mestrado] Niterói: Universidade Federal Fluminense, 2014.

VIVEIROS DE CASTRO, Eduardo. From the Enemy's point of view: Humanity and Divinity in an Amazonian Society. Londres: University of Chicago Press, 1992.

VIVEIROS DE CASTRO, Eduardo. A inconstância da alma selvagem: e outros ensaios de antropologia. São Paulo: Cosac e Naify. 2002.

VIVEIROS DE CASTRO, Eduardo. O recado da mata. Prefácio à edição portuguesa do livro. In: KOPENAWA, Davi; ALBERT, Bruce. A queda do céu: Palavras de um xamã Yanomami. São Paulo: Companhia das letras, 2015. [2010]

VIVEIROS DE CASTRO, Eduardo. Metafísicas canibais. Elementos para uma antropologia pós-estrutural. Ubu editora. N-1 Edições. São Paulo: 2018. 